\title{
Excessive Turbidity Removal from Textile Effluents Using Electrocoagulation Technique
}

\author{
S. M. N. Islam*, S. H. Rahman, M. M. Rahman, T. M. Adyel, R. A. Yesmin, M. S. Ahmed, and \\ N. Kaiser
}

Department of Environmental Sciences, Jahangirnagar University, Savar, Dhaka, Bangladesh

Received 25 April 2011, accepted in revised form 31 May 2011

\begin{abstract}
The work was conducted for improving textile effluent quality via turbidity removal by electrocoagulation (EC) using aluminum sacrificial electrode. Effluents were treated at 30 minutes and 30 volts $(30 \mathrm{~min}-30 \mathrm{~V})$ and 60 minutes and 40 volts $(60 \mathrm{~min}-40 \mathrm{~V})$ condition in a $1000 \mathrm{ml}$ reactor cell with anode distance of $4 \mathrm{~cm}$. Prior to EC experiment, physico-chemical parameters of effluent were measured and turbidity level was found eight times higher than the Department of Environment (DoE) standard. Turbidity removal ranged from 53 to $96.2 \%$ and 58 to $97.5 \%$ for condition one and two, respectively. Dissolved oxygen (DO) increased satisfactorily for both conditions. Total operational cost ranged from 62.50 to $70.41 \mathrm{taka} / \mathrm{m}^{3}$ at $30 \mathrm{~min}-30 \mathrm{~V}$ and 159.57 to $187.7 \mathrm{taka} / \mathrm{m}^{3}$ at $60 \mathrm{~min}-40 \mathrm{~V}$. Moreover, sludge formation ranged from $6.73 \times 10^{-4}$ to $8.41 \times 10^{-4} \mathrm{~kg}$ in first condition and $1.21 \times 10^{-3}$ to $1.5431 \times 10^{-3} \mathrm{~kg}$ in second one. So, EC treatment was very effective and capable of elevating quality of the textile wastewater effluent in terms of turbidity to discharge into inland surface water. During EC operation it was also possible to lessen the total cost in maximum removal by changing the operating condition and 30min-30V was enough to get environmental friendly solution. Results will encourage the industry-owner to treat polluted effluents by EC.
\end{abstract}

Keywords: Textile industry; ETP; Electrocoagulation; Sacrificial Electrode; Turbidity; Operational cost.

(C) 2011 JSR Publications. ISSN: 2070-0237 (Print); 2070-0245 (Online). All rights reserved.

doi:10.3329/jsr.v3i3.7533 J. Sci. Res. 3 (3), 557-568 (2011)

\section{Introduction}

Textile industries are one of the largest and vital industrial sectors of Bangladesh with regard to earn foreign exchange and labor employment, providing 4.5 million jobs of which $80 \%$ are women and contributes $13 \%$ to GDP [1]. This industry involves processing or converting raw material into finished cloth materials employing various processes, operations and consumes large quantities of water and produces extremely polluting waste effluents mostly by dyes and chemicals [2]. These dyes and chemicals, originating from the various steps of production in textile industry, in water often causes it

\footnotetext{
*Corresponding author: shawun_env_512@yahoo.com
} 
to get turbid or colored. Khan et al. [3] reported that a semi-automated composite textile industry of 10 tone capacity produces $1250 \mathrm{~m}^{3}$ of effluents each day contained high $\mathrm{pH}$, high temperature, high biological oxygen demand (BOD), high chemical oxygen demand (COD), high turbidity, low dissolved oxygen (DO) and high concentrations of suspended solids (SS). Under the Bangladesh Environment Conservation Act (1995) and Rules (1997) textile industries must treat as well as monitor the quality of their wastewater and stay within national discharge quality standards [4]. A wide range of wastewater treatment techniques are known which includes biological and physicochemical processes that require chemical additions. The commonly used physico-chemical treatment processes are filtration, air stripping, ion-exchange, chemical precipitation, chemical oxidation, carbon adsorption, ultrafiltration, reverse osmosis, electrodialysis, volatilization and gas stripping [5]. But these methods consist of some disadvantages in terms of large chemical addition, sludge generation, economical viability and sometimes secondary pollution may arise [6].

Halimur Rahman (H.R.) Textile Ltd., located in Savar upazila in Dhaka district with a geographic location N 23 49 '3" and E 90 15 '27.72" surrounded by Karnapara canal, is one of the leading textile industries of Bangladesh. This industry is complying with the national environmental law for effluent using a typical treatment system based on chemical [7]. In this system polyaluminium chloride (PAC) is used as coagulating agent along with the polyacryl amide (PAM) polymer and hydrochloric acid. But due to some disadvantages described elsewhere [5, 6] innovative, cheap and effective methods to clean industrial effluents before discharging into any other systems are needed [5].

A host of very promising techniques based on electrochemical technology are being developed and existing ones improved that do not require chemical additions. One of these, electrocoagulation (EC), has reached profitable commercialization. This method is increasingly gaining popularity because of its environmental compatibility, high particulate removal efficiency, versatility, energy efficiency, safety, selectivity and amenability to automation, low amount sludge generating and cost effectiveness [5, 8-11]. EC has been proposed and adopted for the treatment of various wastewater such as wastewater containing food and protein wastes [12], textile wastewater [8, 13], oil mill wastewater [14], urban wastewater [13], heavy metal laden wastewater [15], nitrite effluent [16], aqueous suspensions containing kaolinite, bentonite, and ultra fine particles $[17,18]$, fluoride containing water [19], restaurant wastewater [20], textile dye solution [21, 22], smelter wastewater containing arsenic [23], landfill leachate [24], saline wastewater [25], tar sand and oil shale wastewater [26], laundry wastewater [27], potable water [28], potato chips wastewater [10], poultry slaughterhouse wastewater [8], boron containing water [29], alcohol distillery wastewater [30], sulfide [31] etc. But in Bangladesh, most of the industry owner is not keen to operate effluent treatment plant (ETP) due to high operating cost and very few (like H.R. Textile Ltd.) operates chemical based ETP. So, as the part of our continuing research, in this paper we tried to investigate the removal efficiency of turbidity and increasing the DO of H.R. Textile Ltd. effluents using EC technique. We also calculated the operating cost for EC. 


\section{EC and Wastewater Treatment}

EC involves dissolution of metal from the anode with simultaneous formation of hydroxyl ions and hydrogen gas occurring at the cathode. In recent years, many investigations have been especially focused on the use of EC owing to the increase in environmental restrictions on effluent wastewater [11]. In EC, coagulants are produced in situ within the reactor without direct addition of any chemicals. Coagulants are produced by the electrolytic oxidation of appropriate anode materials, such as iron and aluminum electrodes, which result in formation of highly charged polymeric metal hydroxyl species. A number of studies pointed out differences that in the case of EC, the coagulants produced by the electrolytic oxidation were in the form of both monomeric hydroxide ions and highly charged polymeric metal hydroxyl species, e.g. $\mathrm{Fe}\left(\mathrm{H}_{2} \mathrm{O}\right)_{6}{ }^{3+}, \mathrm{Fe}\left(\mathrm{H}_{2} \mathrm{O}\right)_{5}(\mathrm{OH})^{2+}$, $\mathrm{Fe}\left(\mathrm{H}_{2} \mathrm{O}\right)_{4}(\mathrm{OH})^{2+}, \mathrm{Fe}_{2}\left(\mathrm{H}_{2} \mathrm{O}\right)_{8}(\mathrm{OH})^{24+}$ and $\mathrm{Fe}_{2}\left(\mathrm{H}_{2} \mathrm{O}\right)_{6}(\mathrm{OH})_{4}{ }^{4+}$, for anodes made of iron and $\mathrm{Al}_{2}(\mathrm{OH})_{2}{ }^{4+}, \mathrm{Al}_{3}(\mathrm{OH})_{4}{ }^{5+}$ and $\mathrm{Al}_{13} \mathrm{O}_{4}(\mathrm{OH})_{24}{ }^{7+}$, for anodes made of aluminum [31]. These species neutralize the electrostatic charges on the suspended solids and facilitate agglomeration resulting in separation from the aqueous phase. So the technology removes colloids particles pollutants from aqueous media by introducing highly charged polymeric hydroxide species. On the whole, the EC process involves three successive stages [5], (a) formation of coagulants by electrolytic oxidation of the sacrificial anode electrodes,

(b) destabilization of the contaminants, particulate suspension, and breaking of emulsions, and (c) aggregation of the destabilized phases to form flocs.

\section{Methods and Materials}

\subsection{Sampling}

Effluents samples were collected before treatment (at equalizer tank) from H.R. Textile Ltd. Samples were taken at eight different days to evaluate the effluent quality variation in different days and after collection samples are brought to laboratory and physic-chemical parameters were analyzed. Samples were preserved until further analysis by EC.

\subsection{Physico-chemical parameters determination}

Physico-chemical parameters of effluents like temperature, $\mathrm{pH}$, electric conductivity (EC), salinity, dissolved oxygen (DO), total dissolved solids (TDS), turbidity were determined using mercury thermometer, glass electrode $\mathrm{pH}$ meter (Ecoson Ion Meter, Model:1161795), conductivity meter (HANNA, Model: HI 8033), conductivity meter (HANNA, Model: HI 8033), DO meter (Eutech Instrument Cyberscan 110), TDS meter (HANNA, Model: HI 8734), micro processor turbidity meter (HANNA, Model: HI 93703), respectively. 


\subsection{EC experimental protocol}

Experiments were carried out in a glass beaker of $1000 \mathrm{ml}$. Aluminum electrodes of $(5.5 \mathrm{~cm} \times 3.8 \mathrm{~cm} \times 0.1 \mathrm{~cm})$ with a distance of $4 \mathrm{~cm}$ and reaction area of about $(3.8 \times 2.9 \times 0.1)$ $\mathrm{cm}$ were used. In preliminary investigation it was found that at $4 \mathrm{~cm}$ electrode distance, maximum turbidity removal and less sludge generation was achieved. The anode was connected with a voltmeter that gives voltage. A voltage stabilizer and an ammeter were used to regulate the flow of electricity and examine the current flow, respectively (Fig. 1). The electricity was measured in every five minutes and it was averaged to get the exact value in $\mathrm{mA}$. $450 \mathrm{ml}$ wastewater was treated at two operational conditions - (a) 30 minutes and 30 volts (30min-30V) and (b) 60 minutes and 40 volts (60min-40V). It is pre assumed that the turbidity and DO in the effluents of eight days will be in little variation. So, the first four days samples were treated at first operating condition and the remaining four days samples at the second operating condition. The electrodes were scrubbed with sand paper and washed with dilute acid to remove impurities on the metal surface. The anode was weighted before and after the experiment for each run to estimate the electrode consumption. At the end of the each experiment run, the treated effluents were filtered with a pre-weighted filter paper. Filter paper was dried in oven and generated sludge amount was measured after subtracting the initial weight from final weight.

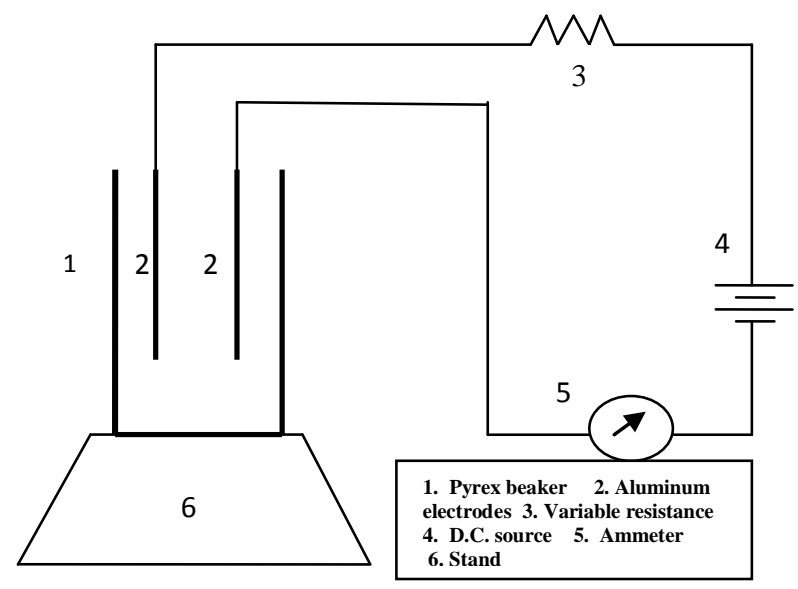

Fig. 1. Schematic diagram of electrocoagulation (EC) experiment.

\section{Results and Discussion}

\subsection{Physico-chemical parameters of effluents}

The effluents were reddish orange in color and pungent in odor. Average temperature was around $36^{\circ} \mathrm{C}$ and $\mathrm{pH}$ of all samples was around 9.5 (slightly basic in nature). Electrical 
conductivity and TDS were $4440 \mu \mathrm{S} / \mathrm{cm}$ and $2130 \mathrm{mg} / \mathrm{l}$, respectively. Turbidity and DO values varied from 45.76 to $37.39 \mathrm{FTU}$ and 0.93 to $1.25 \mathrm{mg} / \mathrm{l}$, respectively. All these parameters except temperature and $\mathrm{pH}$ significantly violate the national standard set by the Department of Environment (DoE) for inland surface water [32]. The standard value of temperature, $\mathrm{pH}$, electrical conductivity, TDS, turbidity and DO for discharging into the inland surface water is $40^{\circ} \mathrm{C}, 6-9,1200 \mu \mathrm{S} / \mathrm{cm}, 2100 \mathrm{mg} / \mathrm{l}, 5 \mathrm{FTU}$ and $4.5-8 \mathrm{mg} / \mathrm{l}$, respectively.

\subsection{Increase of DO}

Dissolved oxygen (DO) levels in natural wastewaters depend on the physical, chemical, and biochemical activities in the water body. All the samples contained very low DO level than DoE standard. For aquatic life DO is very important for its survival. So discharge of these effluents to the water bodies or other compartments of the environment will be harmful. For first operational condition, DO increased from 0.96, 1.12, 1.15 and $0.93 \mathrm{mg} / \mathrm{l}$ to $5.95,3.08,4.18$ and $3.83 \mathrm{mg} / \mathrm{l}$ for samples S1, S2, S3 and S4, respectively. In second operational condition DO increased from 1.12, 1.25, 1.10 and $0.98 \mathrm{mg} / \mathrm{l}$ to 3.70, 4.37, 4.52 and $7.75 \mathrm{mg} / \mathrm{l}$ for samples S1, S2, S3 and S4, respectively (Fig. 2). S1 of first condition and S3 and S4 of later one followed the DoE standard for discharging into inland surface water. DO increased due to removal of pollutants load from the effluent samples by coagulation of EC technique. At 30min-30V condition DO increased about 520, 175, 264 and 312\% for S1, S2, S3 and S4, respectively. 208, 250, 311 and 691\% DO increased for S1, S2, S3 and S4, respectively at 60min-40V condition (Fig. 2).

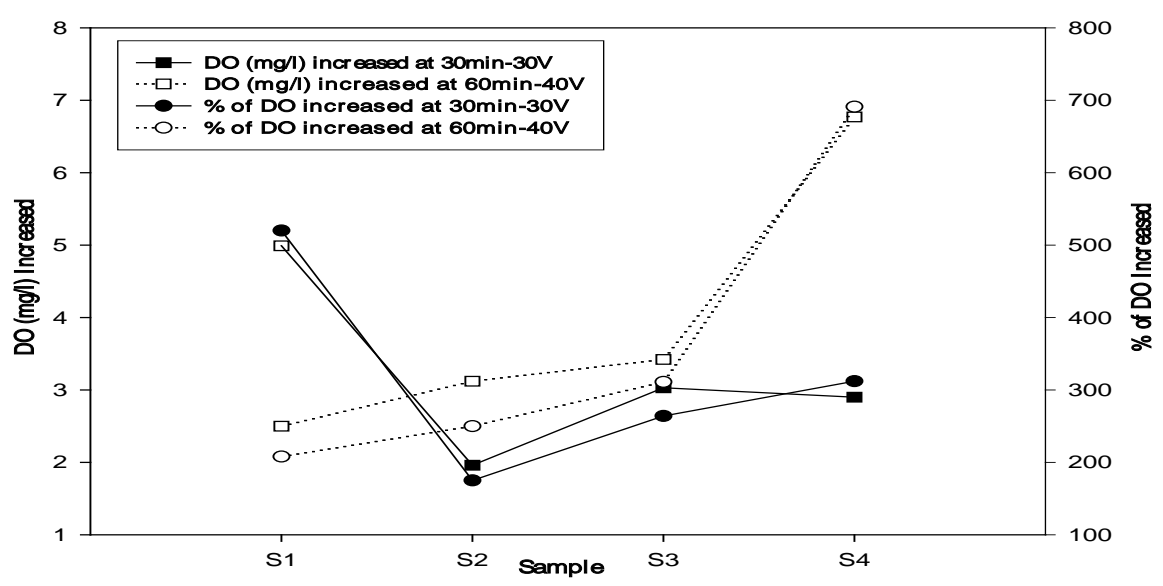

Fig. 2. Sample wise increase and increasing percentage of DO. 


\subsection{Turbidity removal}

Turbidity is an important aspect of textile wastewater. Sample effluents contained higher amount of turbidity than the standard of DoE (5 FTU) and needs treatment to safely discharge in the surface water. Turbidity removed in EC process was good. In case of 30min-30V, turbidity decreased from 45.76, 41.17, 41.60 and 40.56 FTU to 1.75, 6.10, 7.75 and 19.28 FTU for samples S1, S2, S3 and S4, respectively. At 60min-40V, turbidity removed from 37.39, 38.62, 39.42 and 40.19 FTU to 0.95, 5.84, 14.25 and 17.03 FTU for sample S1, S2, S3 and S4, respectively (Fig. 3). Turbidity removal percentage was achieved from 53 to $96 \%$ at $30 \mathrm{~min}-30 \mathrm{~V}$ with an average of $79 \%$ removal. 58 to $97 \%$ turbidity removal was achieved at $60 \mathrm{~min}-40 \mathrm{~V}$ with an average removal of $76 \%$ (Fig. 3).

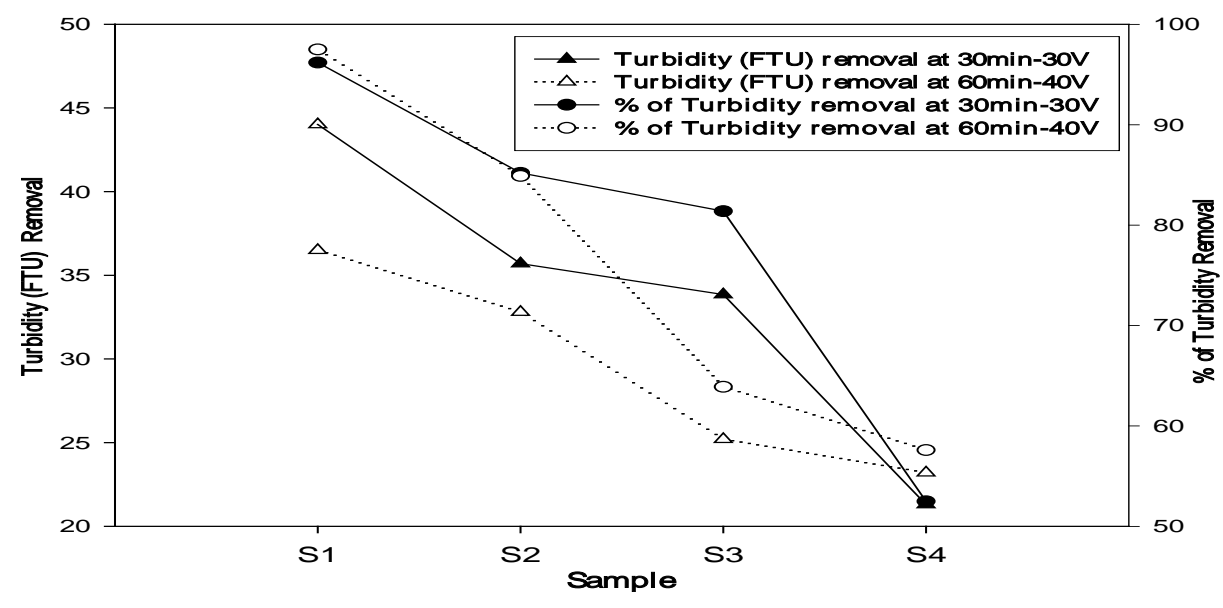

Fig. 3. Sample wise turbidity removal and removal percentage.

The two main aims of the coagulation are: (i) to settle the suspended colloidal particles in water/wastewater rapidly, which settle very slowly, or perhaps do not settle at all under normal conditions, hence leading to residual turbidity, and (ii) to remove residual turbidity from the water/wastewater and consequently to obtain clearer water/wastewater, which is a natural outcome of the former [33].

The current density is a parameter that controls the anode dissolution speed on the one hand, and that of hydrogen formation on the other hand [20, 3-36]. In all electrochemical processes, current density determines the coagulant production rate, and adjusts the rate and size of the bubble production and hence affects the growth of flocs [37]. In an EC experiment the electrode or electrode assembly is usually connected to an external DC source. The amount of metal dissolved or deposited is dependent on the quantity of electricity passed through the electrolytic solution. A simple relationship between current density and the amount of substances dissolved can be derived from Faraday's law as Eq. (1), 


$$
w=I t M / z F
$$

where $w$ is quantity of electrode material dissolved $(\mathrm{kg}), I$ is current density $\left(\mathrm{A} / \mathrm{m}^{2}\right), t$ is time (h), $M$ is relative molar mass of the electrode concerned, $n$ is number of electrons in oxidation/reduction reaction and $F$ is the Faraday's constant $(96487 \mathrm{C} / \mathrm{mol})$. The electricity used in the whole operation of EC was not so variable. Electric current varied from 0.68 to $0.87 \mathrm{~mA}$ for $30 \mathrm{~min}-30 \mathrm{~V}$ and 0.68 to $0.80 \mathrm{~mA}$ for $60 \mathrm{~min}-40 \mathrm{~V}$, respectively (Fig. 4). Anode dissociated from $1.62 \times 10^{-4}$ to $0.1 .69 \times 10^{-4} \mathrm{~kg}$ for $30 \mathrm{~min}-30 \mathrm{~V}$ and from $3.02 \times 10^{-4}$ to $4.863 \times 10^{-4} \mathrm{~kg}$ for $60 \mathrm{~min}-40 \mathrm{~V}$, respectively (Fig. 4).

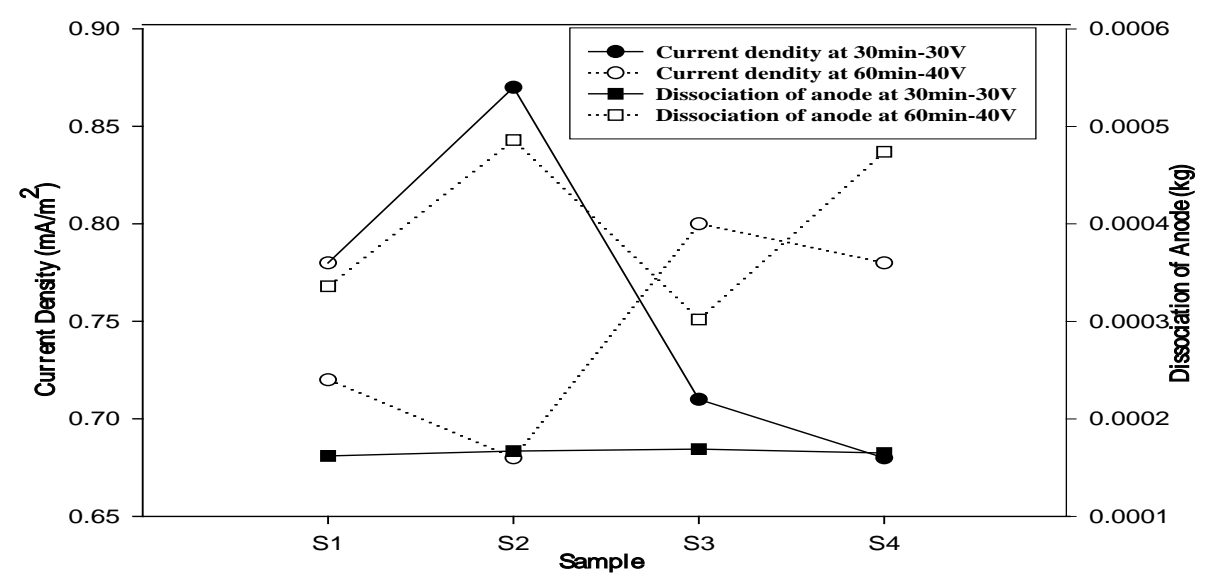

Fig. 4. Current density and dissociated of anode at different operating conditions.

$\mathrm{Al}$ is dissociated from the anode generating corresponding metal ions, which almost immediately hydrolyze to form excellent coagulating agent i.e., polymeric aluminum hydroxide. The sacrificial metal anodes are used to continuously produce polymeric hydroxides in the vicinity of the anode. Coagulation occurs when these metal cations combine with the negative particles carried toward the anode by electrophoretic motion. Contaminants present in the wastewater stream are treated either by chemical reactions and precipitation or physical and chemical attachment to colloidal materials being generated by the electrode erosion. They are then removed by electroflotation, or sedimentation and filtration [5]. Thus, rather than adding coagulating chemicals as in conventional coagulation process, these coagulating agents are generated in situ.

Szpyrkowicz [38] showed that the turbidity removal occurs as the result of destabilization of colloids due to the effect of the electric field generated between the electrodes and the reactions with coagulating compounds formed in situ during anode oxidation, followed by a subsequent flotation of agglomerates of the particles. It is thought that increasing electrolyze time or current intensity improves the efficiency of 
turbidity removal by faster producing hydrolyze products. During electrochemical treatment, when a potential is applied between electrodes, hydroxyl ions and $\mathrm{Al}^{3+}$ are generated at the cathode and anode, respectively. These products are responsible for coagulation. The possible combination of various hydrolysis products is endless and one or more of them may be responsible for the observed action of flocculation [38, 39]. Aluminum upon oxidation in an electrolytic system produces aluminium hydroxide, $\mathrm{Al}(\mathrm{OH})_{\mathrm{n}}$ where $\mathrm{n}=2$ or 3 [40].

Anode:

$$
\begin{aligned}
& 2 \mathrm{Al} \rightarrow 2 \mathrm{Al}^{3+}(\mathrm{aq})+6 \mathrm{e}^{-} \\
& 2 \mathrm{Al}^{3+}(\mathrm{aq})+6 \mathrm{H}_{2} \mathrm{O}(\mathrm{l}) \rightarrow 2 \mathrm{Al}(\mathrm{OH})_{3}(\mathrm{~s})+6 \mathrm{H}^{+}(\mathrm{aq})
\end{aligned}
$$

Cathode:

$6 \mathrm{H}^{+}(\mathrm{aq})+6 \mathrm{e}^{-} \rightarrow 3 \mathrm{H}_{2}(\mathrm{~g})$

Overall:

$$
2 \mathrm{Al}(\mathrm{s})+6 \mathrm{H}_{2} \mathrm{O}(\mathrm{l}) \rightarrow 2 \mathrm{Al}(\mathrm{OH})_{3}(\mathrm{~s})+3 \mathrm{H}_{2}(\mathrm{~g})
$$

Some type of sorption mechanism occurs during turbidity removal by EC process [41]. After the colloidal suspension has been destabilized, effective aggregation requires adequate contact between the coagulant and pollutant particles. Consequently, the transport mechanism is important as this determines the transportation of, including collisions between, particles coagulant and bubbles. Thus the fluid regime clearly has a significant impact on both the flocculation mechanism and the subsequent means of pollutant removal [42].

Increase in retention time increases the efficiency of turbidity removal and this is because of precipitation of flocs that cause removal of turbidity particles. With increase of electrical current, the efficiency of turbidity removal increases. In high voltages, size and growth rate of produced flocs increase and this in turn affects the efficiency of the process [19]. By electrical potential increase the amount of oxidized aluminum increases and consequently hydroxide flocs with high adsorption rate increase and this leads to an increase in the efficiency of pollutant removal [43]. On the other hand, by electrical current increase, the density of bubbles increases while their size decreases hence the flotation efficiency increases [44]. But, in this experiment for simplification we just introduced two operating conditions (time and voltage variation) and from the treatment efficiency under these conditions it was infer that first operating condition was well enough to remove turbidity and increase DO up to national standard. Similar findings also reported by other investigators [45]. EC is more efficient than chemical coagulant for turbidity removal. Belongia et al. [46] highlighted that EC removed turbidity about $96.5 \%$ in less than 30 minutes. But, these all experiments were carried out in laboratory scale. Large scale experiment is very necessary to find out the effectiveness of laboratory scale findings of real samples and it is our main objective for further research planning. So, due to the simplification of present development in maximum pollutant removal, EC 
system has a good scope to replace chemical based treatment system used in a typical industry like H.R. Textile Ltd.

\subsection{Sludge generation and operational cost}

EC is characterized for low sludge generation than the conventional chemical coagulation and other treatment systems. In present experiment of $450 \mathrm{ml}$ samples, sludge generation ranged from $6.73 \times 10^{-4}$ to $8.41 \times 10^{-4} \mathrm{~kg}$ at first condition and $1.21 \times 10^{-3}$ to $1.5431 \times 10^{-3} \mathrm{~kg}$ at second one. Sludge formation increased with increasing voltage and time. For EC technique main operational cost included electricity and electrodes cost and for present work this cost was calculated by Eq. 6 to Eq. 8, modified after Ghosh et al. [47].

$$
\begin{aligned}
& \text { Operating cost }=a C_{\text {energy }}+b C_{\text {electrode }} \\
& C_{\text {energy }}=U I t_{E C} v \\
& C_{\text {electrode }}=M_{W} I t_{E C} / z F v
\end{aligned}
$$

where, $U$ is cell voltage $(\mathrm{V}), I$ is current $(\mathrm{A}), t_{\mathrm{EC}}$ is time of electrocoagulation (h), $v$ is volume of sample $\left(\mathrm{m}^{3}\right), F$ is the Farady's constant $(96487 \mathrm{C} / \mathrm{mol}), M_{\mathrm{W}}$ is molecular weight of aluminium $(26.98 \mathrm{~g} / \mathrm{mol}), \mathrm{z}$ is number of electron transferred $(\mathrm{z}=3), a$ is electricity energy price (2.64 taka/kWh) and $b$ is electrode material price (300 taka/kg Al). Electricity consumption in condition one ranged from 23.7 to $29 \mathrm{kWh}$ with an average of $26.35 \mathrm{kWh}$, while the value ranged from 60.44 to $67.55 \mathrm{kWh}$ with an average of 65.78 $\mathrm{kWh}$ in second condition. Anode consumption was very low for both cases (fig. 5). Total operational cost ranged from 62.50 to $70.41 \mathrm{taka} / \mathrm{m}^{3}$ for EC at $30 \mathrm{~min}-30 \mathrm{~V}$. It took 159.57 to $187.7 \mathrm{taka} / \mathrm{m}^{3}$ for EC at $60 \mathrm{~min}-40 \mathrm{~V}$. More voltage, electrolysis time was applied in second case and hence total cost was higher compared to first case (Fig. 5, inset).

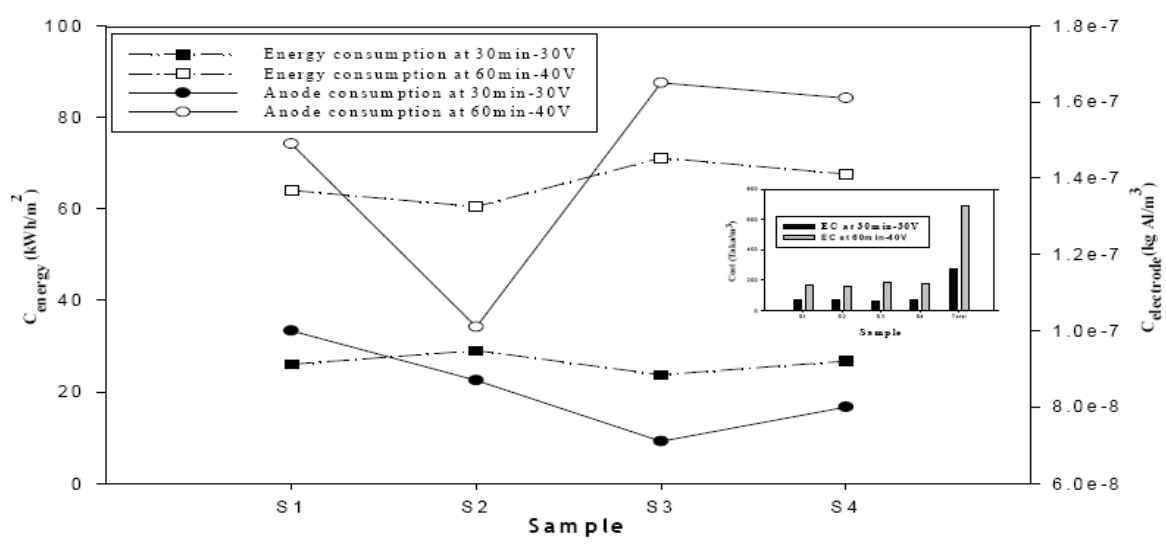

Fig. 5. Electricity and anode consumption at different operating conditions. 
Ghosh et al. [47] also calculated the operating cost in pollutant removal through EC and they proposed almost the same cost of present investigation.

\section{Conclusion}

EC is the process of treating suspended, emulsified or dissolved contaminants in an aqueous medium by introducing an electric current into the medium. EC is one of the most effective techniques to remove turbidity and pollutants from wastewater and this technique was influenced by electrode material, electrical potential and electrolysis time. Between the two operating conditions, 30min-30V was seemed to be good enough for transferring turbidity and DO from polluted situation into unpolluted condition. Turbidity removal by EC was up to $96 \%$ and $97 \%$ at $30 \mathrm{~min}-30 \mathrm{~V}$ and $60 \mathrm{~min}-40 \mathrm{~V}$, respectively. Total operating cost was relatively low (ranged from 62.50 to $70.41 \mathrm{taka} / \mathrm{m}^{3}$ at $30 \mathrm{~min}-30 \mathrm{~V}$ and from 159.57 to $187.7 \mathrm{taka} / \mathrm{m}^{3}$ at $60 \mathrm{~min}-40 \mathrm{~V}$ ) comparing other treatment system. Operating condition was environmental compatibility as sludge generation was low. Finally, based on experimental data and since no precipitating agents were applied like other conventional treatment system, the EC process proved to be not only feasible and environmentally friendly but also a cost-effective technology for a typical textile industry.

\section{Acknowledgement}

The authors are highly grateful to Professor Dr. M. Yousuf A. Mollah, University of Dhaka for his kind help in experimental setup. Thanks also go to Mr. Kamol K. Das of Purdue University, USA, for his inspiration to carry out this work.

\section{References}

1 Bangladesh Textile Mills Association (BTMA), Annual Report, (2007).

2. A. A. Rahman, M. I. Sharif, M. A. Mahmood, M. S. Khan, N. S. Chowdhury, R. Sultana, S. Ahmed and M. Rahman, Textile Dyeing and Effluent Treatment, Bangladesh Centre for Advanced Studies (BCAS), Dhaka, (2007).

3. M. Khan, J. Knapp, A. Clemett and M. Chadwick, Managing Pollution from Small Industries in Bangladesh, Technical Report, Research for Development, Department for International Development (DFID), (2006).

4. M. S. Khan, S. Ahmed, A. E. V. Evans and M. Chadwick, Chem. Eng. Res. Bull. 13, 61 (2009). doi:10.3329/cerb.v13i2.3939

5. M. Y. A. Mollah, P. Morkovsky, J. A. G. Gomes, M. Kesmez, J. Pargad and D. L. Cocke, J. Hazard. Mater. B114, 199 (2004). doi:10.1016/j.jhazmat.2004.08.009

6. L. Heidmann and W. Calmano, Sep. Purif. Technol. 61, 15 (2008). doi:10.1016/j.seppur.2007.09.011

7. M. M. Rahman, H.R.Textile Ltd, Personal communication (2011).

8. O. T. Can, M. Bayramoglu and M. Kobya, Ind. Engi. Che. Res 42, 3391 (2003). doi:10.1021/ie020951g

9. P. Ca nnizarez, R. Paz, J. Lobato, C. Saéz and M. A. Rodrigo, J. Hazard. Mater. 138, 173 (2006).

10. M. Y. A. Mollah, R. Schennach, J. R. Parga and D. L. Cocke, J. Hazard. Mater. 84, 29 (2001). $\underline{\text { doi:10.1016/S0304-3894(01)00176-5 }}$ 
11. F. Zidane, P. Drogui, B. Lekhlif, J. Bensaid, J. ois Blais, S. Belcadi and K. El kacemi, J. Hazard. Mater. 155, 153 (2008). doi:10.1016/j.jhazmat.2007.11.041

12. J. S. Do and M. L. Chen, J. App. Electrochem. 24, 781 (1994).

13. S. H. Lin and C. Peng, Water Res. 28 (2), 277 (1994). doi:10.1016/0043-1354(94)90264-X

14. H. Inan, A. Dimoglo, H. Simsek and M. Karpuzcu, Sep. Purif. Technol. 36, 23 (2004). doi:10.1016/S1383-5866(03)00148-5

15. C. L. Lai and S. H. Lin, Che. Eng. J. 95, 205 (2003). doi:10.1016/S1385-8947(03)00106-2

16. A. S. Koparal and U. B. Ogutveren, J. Hazard. Mater. 89, 83 (2002). doi:10.1016/S0304-3894(01)00301-6

17. J. C. Donini, J. J. Kan, J. Szynkarczuk, T. A. Hassan and K. L. Kar, Can. J. Chem. Eng. 72, 1007 (1994). doi:10.1002/cjce.5450720610

18. M. J. Matteson, R. L. Dobson, R. W. Glenn Jr, N. S. Kuku Jr, W. H. Waits III and E. J. Clayfield, Colloids Surf. 104, 101 (1995). doi:10.1016/0927-7757(95)03259-G

19. J. Zhu, H. Zhao and J. Ni, Sep. Purif. Technol.56 (2), 184 (2007). doi:10.1016/j.seppur.2007.01.030

20. X. Chen, G. Chen and P. L. Yue, Sep Purif. Technol. 19, 65 (2000). doi:10.1016/S1383-5866(99)00072-6

21. U. B. Ogutveren, N. Gonen and S. Koparal, J. Env. Sci. and Health A 27 (5), 1237 (1992). doi:10.1080/10934529209375794

22. Y. Xiong, P. J. Strunk, H. Xia, X. Zhu and H. T. Karlsson, Water Res. 35, 4226 (2001). doi:10.1016/S0043-1354(01)00147-6

23. N. Balasubramanian and K. Madhavan, Chem. Eng. Tech. 24, 519 (2001). doi:10.1002/1521-4125(200105)24:5<519::AID-CEAT519>3.0.CO;2-P

24. C. T. Tsai, S. T. Lin, Y. C. Shue and P. L. Su, Water Res. 31, 3073 (1997). doi:10.1016/S0043-1354(96)00297-7

25. S. H. Lin, C. T. Shyu and M. C. Sun, Water Res. 32, 1059 (1998). doi:10.1016/S0043-1354(97)00327-8

26. R. R. Renk, Energy Prog. 8, 205 (1988).

27. J. Ge, J. Qu, P. Lei and H. Liu, Sep. Purif. Technol.36, 33 (2004). doi:10.1016/S1383-5866(03)00150-3

28. E. A. Vik, D. A. Carlson, A. S. Eikun and E. T. Gjessing, Water Res. 18, 1355 (1984). doi:10.1016/0043-1354(84)90003-4

29. A. Erdem, Y. Recep and B. M. M. Kocakerim, J. Hazard. Mater. 144 (1- 2), 101 (2007).

30. Y. Yavruz, Sep. Purif. Technol. 53, 135 (2006). doi:10.1016/j.seppur.2006.08.022

31. M. Muruganathan, G Bhaskar, G. Raju and S. Prabhakar, J. Hazard. Mater. B109, 37 (2004). doi:10.1016/j.jhazmat.2003.12.009

32. M. E. Haque, A compilation of environmental laws of Bangladesh. Administrated by the Department of Environment (DoE), (2003).

33. B. Ersoy, I. Tosun, A. Gunay and S. Dikmen, Clean 37 (3), 225 (2009).

34. R. Sherestha, R. Fischer and D. Rahner, Colloids Surf. A222, 261 (2003). doi:10.1016/S0927-7757(03)00231-0

35. M. Kobya, O. T. Can and M. Bayramoglu, J. Hazard. Mater. 100, 163, (2003). doi:10.1016/S0304-3894(03)00102-X

36. N. Daneshvar, A. H. Sorkhabi and M. B. Kasiri, J. Hazard. Mater. B112 (1-2), 55 (2004). doi:10.1016/j.jhazmat.2004.03.021

37. N. Daneshvar, A. H. Sorkhabi and A. Tizpar, Sep. Purif. Technol. 3, 153 (2003). doi:10.1016/S1383-5866(02)00178-8

38. L. Szpyrkowicz, J. of Ann. Chim. 92(10), 1025 (2002).

39. E. R. Alley, Water quality control handbook (McGraw-Hill, New York, 2000).

40. A. Biwyk, World Congress of Chemical Engineering. Karlsruhe, Germany (1991) pp.16-49.

41. R. D. Letterman, A. Amirtharajah, and C. R. O'Melia, Coagulation and flocculation in water quality and treatment, In: ed R.D. Letterman (A Handbook of Community Water Supplies, AWWA, McGraw-Hill, New York, 1999). 
42. P. K. Holt, G. W. Barton, M. Wark and C. A. Mitchell, Colloid Surf A. 211 (2-3), 233 (2002).

43. K. P. Ranta, S. Chaudhary, K. C. Khilar and S. P. Mahajan, Chemos, 55 (9), 1245 (2004). doi:10.1016/j.chemosphere.2003.12.025

44. C. Y. Hu, S. L. Lo and W. H. Kuan, Water Res. 39 (5), 895 (2005). doi:10.1016/j.watres.2004.11.034

45. M. Han, J. Song and A. Kwon, J. Water Supply 2(5-6), 73 (2002).

46. B. M. Belongia, P. D. Haworth, J. C. Baygents and S. Raghavan, J. Electroche. Society 146 (11), 4124 (1999).

47. D. Ghosh, H. Solanki and M. K. Purkait, J. Hazard. Mater. 155, 135 (2008). doi:10.1016/j.jhazmat.2007.11.042 